\title{
Research On the Multiscale Characteristics of the Early Spring Temperature and Response To Climate Indices Over the Past 179 Years in the Qinling Mountains
}

Chenhua Zhang

Northwest University https://orcid.org/0000-0002-5260-3132

Jiachuan Wang

Northwest University

Shuheng Li ( $\square$ lish@nwu.edu.cn )

Northwest University

Li Hou

Northwest University

\section{Research Article}

Keywords: Temperature, Ensemble empirical mode decomposition, Time scale, Qinling Mountains

Posted Date: November 9th, 2021

DOl: https://doi.org/10.21203/rs.3.rs-931416/v1

License: (c) (i) This work is licensed under a Creative Commons Attribution 4.0 International License.

Read Full License 


\section{Abstract}

Examination of the periodic differences in temperature in the Qinling Mountains at different time scales is highly important in research on the long-term evolution of the regional climate system and ecological environment. Based on February-April temperature data from 1835 to 2013 obtained at 27 weather stations in the Qinling Mountains reconstructed through tree rings, the multiscale characteristics of the early spring temperature time series on the southern and northern slopes of the Qinling Mountains and the response to climate signals were analyzed. The results indicate that the early spring temperature in the Qinling Mountains exhibits significant periodic characteristics on multiple time scales. Reconstruction at the different time scales reveals that the interannual scale change in the temperature variation on the northern slope of the Qinling Mountains plays a decisive role. The temperature on the northern slope exhibits a higher amplitude at the interannual and interdecadal scales than does that on the southern slope, and temporal differences occur at the quasi-century scale. The temperature achieves the strongest correlation with the original Atlantic Multidecadal Oscillation (AMO) sequence during the entire study period. In addition, the different time scales reveal that there exists a significant response relationship between the temperature at the interannual scale and the May sea temperature in the NINO3.4 area, which lags by one year. At the different time scales and various time ranges, the Qinling early spring temperature responds differently to the climate signals, which is an important factor leading to a lower correlation during the entire study period.

\section{Introduction}

The Qinling Mountains, as an important north-south geographic boundary in China, are extremely sensitive to climate change. Therefore, this region has become a typical area for climate change research. The north-south temperature change difference is representative of the temperature variation in China and even in the Northern Hemisphere (Li et al. 2012; Zhou et al. 2011; Wang et al. 2021). Many scholars have carried out numerous studies on temperature changes at single points or areas during different research periods based on instrumental and proxy data, such as loess, tree ring, and lake sediment data, focusing on the temporal and spatial changes in temperature in the Qinling Mountains ( $\mathrm{Li}$ et al. 2012; Zhou et al. 2011; Wang et al. 2021; Li et al. 2018; Bai et al. 2012; Lei 1999; Zhang et al. 2015; Chen et al. 2013; Garfin et al. 2005). There were differences in the temperature changes between the northern and southern slopes of the Qinling Mountains over the past 50 years (Yan and Zheng 2001). The growth rate on the northern slope was higher than that on the southern slope, and the annual average temperature difference between the northern and southern slopes was gradually reduced. Over the past 122 years, the Qinling Mountains attained a significant correlation with the sea temperature in the tropical western Pacific and other regions (Tian et al. 2011). Previous studies have provided information and a reference to further examine the temporal change trend of the temperature in the Qinling Mountains. However, existing work has mainly focused on the application of traditional statistical methods in temperature change studies, such as linear fitting and moving average methods, to calculate temperature warming trends at a constant rate (Ji et al. 2014). However, in terms of time series, the temperature not only 
exhibits a single linear change or multiple linear changes but also exhibits a complex process involving nonlinear and nonstationary states, including quasiperiodic changes on varying time scales. The multiscale temperature oscillation in long-term series reflects the periodic changes within the climate system, and different periodic changes can reflect cold and warm periods of climate change at multiple scales, which has implications for the study of long-term climate system trends and global warming mitigation. Therefore, it remains important to investigate the periodic changes in the Qinling temperature at different time scales.

In the early spring, winter snow melts in the Qinling Mountains and plants germinate. The temperature fluctuations during this period directly affect vegetation growth in the region, and vegetation changes in turn affect regional climate changes and natural disasters caused by variations. Therefore, studying the multiscale periodic change in the early spring temperature is highly important for the prediction of the temporal evolution trend of plant growth and prevention of the formation of regional climate disasters. Previous studies have indicated that multiscale climate signals, such as the El Niño/Southern Oscillation (ENSO), Pacific Interdecadal Oscillation, North Atlantic Multidecadal Oscillation, and North Atlantic Oscillation, are important factors of global and regional climates through ocean systems or atmospheric circulation (Knight et al. 2006; Xu et al. 2021; Mann et al. 2014). Changes in the above global-scale climate signals can notably affect temperature variations in China and even the Northern Hemisphere (Wyatt and Curry 2014; Jia et al. 2017; Li et al. 2015). In addition, the Qinling regional climate exhibits a good response to ENSO and other indices (Ma et al. 2001), but the different climate signals characteristically experience periodic changes on multiple scales. There is less concern regarding the differences in the temperature response to global climate signal changes at the various time scales.

In this paper, temperature data obtained at 27 meteorological stations in the Qinling area from FebruaryApril 1835 to 2013 reconstructed via the tree-ring width chronology method are employed to conduct multiscale analysis of the 179-year early spring temperature time series pertaining to the southern and northern slopes of Qinling to reveal the multiscale regional changes in temperature against the background of global warming. We analyze the correlation between the temperature and a variety of climate signals on different time scales to study the possible responses of cyclical temperature changes within the context of multiscale global climate changes, explore the nature of regional cyclical temperature changes in depth, and further provide a reference for regional climate prediction.

\section{Research Area, Data And Methods}

\subsection{Overview of the study area and data sources}

The Qinling Mountains $\left(32^{\circ} 40^{\prime} \mathrm{N}-34^{\circ} 35^{\prime} \mathrm{N}, 105^{\circ} 30^{\prime} \mathrm{E}-111^{\circ} 3^{\prime} \mathrm{E}\right)$ comprise the boundary between the north and south and between the subtropical and warm temperate zones in China, and these mountains further contain sensitive ecological environments (Figure. 1). Over the past 60 years, the temperature trend rate on the northern slope of the Qinling Mountains was $0.24^{\circ} \mathrm{C} / 10 \mathrm{a}$, and the temperature trend rate on the southern slope reached $0.15^{\circ} \mathrm{C} / 10$ a (Zhang et al. 2018). 
The temperature data analyzed in this paper include the average temperature at 27 meteorological stations in the Qinling area from February-April 1835 to 2013 reconstructed from 32 tree-ring width chronology data (Hou et al. 2017). The data are established with a linear regression equation, and the data reliability is tested with the one-by-one elimination method. The correlation coefficients of the data retrieved from each meteorological station are all above 0.4 , the complex correlation coefficient and reliability value of the $F$ test both reach 0.99 , and the error reduction value approaches 0.3 . The reliability values, such as the sign test and product average, are above 0.99 . The test results confirm that the reconstruction results are accurate and reliable.

The seven climate signals selected in this paper to study the multiscale response to the Qinling temperature include regional ocean temperatures or large-scale atmospheric circulation phenomena under long-term series, and all these climate signals exhibit periodic changes at different scales.

Monthly average data of these 7 climate signals are acquired from the official website of the National Oceanic and Atmospheric Administration (NOAA) (http//www.noaa.gov) (Table 1).

Table 1 Climate signals

\begin{tabular}{lll} 
Category & Climate signal & Time span \\
\hline $\begin{array}{lll}\text { Sea surface temperature } \\
\text { (SST) }\end{array}$ & El Niño 3.4 district-average SST, & $1854-$ \\
& NINO3.4 & 2013 \\
\cline { 2 - 3 } & Pacific Decadal Oscillation, PDO & $1854-$ \\
& & 2013 \\
\cline { 2 - 3 } & Atlantic Multidecadal Oscillation, AMO & $1874-$ \\
& & 2013 \\
\hline Atmospheric circulation & Northern Atlantic Oscillation, NAO & $1854-$ \\
& & 2013 \\
\cline { 2 - 3 } & Southern Oscillation Index, SOI & $1866-$ \\
& & 2013 \\
\cline { 2 - 3 } & North Pacific Index, NP & $1899-$ \\
& & 2013 \\
\hline Others & Global Average Temperature Anomaly, & $1880-$ \\
& GATA & 2013
\end{tabular}

\subsection{Main research methods}

Ensemble empirical mode decomposition (EEMD) can be employed to extract the change trend of time series at different scales (Wu and Huang 2009; Agbazo et al. 2021). This technique is a new noiseassisted analysis method proposed by Wu and Huang based on the empirical mode decomposition 
(EMD) method (Wei 1999). This method inherits the advantages of the EMD adaptability, addresses the problem of unclear modal separation and extracts climate change signals more truthfully and reliably. This method first adds qualified white noise to the original signal, continuously deepens the signal intensity for cyclic testing and thereafter computes the overall average value to cancel the added white noise. The result is then applied as the final intrinsic mode function (IMF) component of EEMD:

$$
C(t)=\frac{1}{N} \sum_{i=1}^{N} C_{i j}(t)
$$

In equation (1), $C_{j}(t)$ is the $j$-th IMF component obtained via EEMD processing of the original sequence, $N$ is the increase in white noise, and $\mathrm{C}_{\mathrm{ij}}(\mathrm{t})$ is the decomposition result of the $\mathrm{j}$-th IMF component after adding white noise for the i-th time (Wu and Huang 2009). In addition, the EEMD method relies on the mirror extension method to proc0ess data to lower the error caused by the boundary effect. The obtained IMF component can be evaluated with the white noise significance test method to determine whether it provides a clear physical meaning (Wu and Huang 2004; Xue et al. 2013; Wu and Huang 2005).

The time-dependent intrinsic correlation (TDIC) method is a correlation analysis method based on the EEMD method proposed by Chen et al (Chen et al. 2010). This method is suitable to evaluate the relationship between two sets of sequences at different time scales. TDIC analysis first compares the two sets of IMFs decomposed via EEMD and selects those IMFs with similar average periods among the sets of sequences for internal correlation analysis. In the analysis process, the minimum sliding window size for comparison should be clarified, and Student-t test should be performed to verify whether there occurs a significant correlation between the two sets of IMF sequences. In the final established TDIC correlation matrix, the abscissa indicates the time, the ordinate indicates the size of the sliding window, and the part that fails the significance test is shown in the figure (Adrsh 2017). Compared to the traditional correlation analysis method, the advantage of this method is that local correlation between any two data columns can be analyzed to reflect the differences in the correlation between the data during the different periods. In addition, this method calculates the IMF correlation after EEMD application, so it is more suitable to study the correlation of nonlinear and nonstationary time series, which is difficult to accomplish in traditional correlation analysis.

Multiscale temperature reconstruction further explores the change trend of the temperature at the different time scales. This paper adds IMF components at the different time scales to obtain the overall temperature change trend on a given scale. Interannual scale changes are determined by adding IMF components that reflect the interannual period. The decadal scale is obtained by adding IMF components reflecting the interdecadal period. Larger-scale periodic oscillations are obtained by adding IMF components with a scale larger than the decadal period and the trend term RES.

\section{Results And Analysis}

\subsection{Trend characteristics of the temperature changes}


According to Figure 2, over the past 179 years, the temperature tendency rate in the Qinling Mountains reaches $0.013^{\circ} \mathrm{C} / 10$ a on the northern slope and $0.010^{\circ} \mathrm{C} / 10$ a on the southern slope, and the increase rate on the northern slope is slightly higher than that on the southern slope. The temperature anomaly indicates that the temperature fluctuation range on the northern slope is generally larger than that on the southern slope. Except for a large difference in individual years, the temperature on both the southern and northern slopes exhibits a nonlinear and nonsteady increase trend, and the temperature experiences a fluctuation process of increase - decrease - increase - decrease - increase - increase. Since the beginning of this century, there has occurred a notable increase in the number of years with an average temperature $0.5^{\circ} \mathrm{C}$ higher than the average temperature during the study period, which indicates that the probability of extreme temperature events in the Qinling Mountains has considerably increased. Traditional linear trend analysis cannot reflect the true conditions of the temperature fluctuations during the study period. Therefore, a nonlinear research method different from traditional methods should be adopted when studying temperature change in this area.

\subsection{Multiscale changes in the temperature}

With the use of MATLAB2014a software as the platform, the signal-to-noise ratio between the white noise-disturbed and original signals reaches 0.2 , and the number of samples is 100 . During the 179-year study period, the average temperature on the southern and northern slopes of the Qinling Mountains from February to April is multiscaled based on the EEMD method, and 5 IMF components and trend item RES are obtained for both the northern and southern slopes. The eigenmode components of temperature decomposition on the northern slope are denoted as IMFn, and those on the southern slope are denoted as IMFs. These two sets of IMF components in turn reflect the multiscale changes in temperature from a high frequency to a low frequency on the southern and northern slopes of the Qinling Mountains from February to April (Figure. 3). The change in the amplitude indicates the strength of the cycle, which is the result of the joint action of internal movement and external factors of the climate system (Xue et al. 2013). The residual trend item RES reflects the overall trend over time of the temperature changes during the study period.

Figure 3 shows that the early spring temperature in the Qinling Mountains exhibits periodic oscillations at the various time scales, such as interannual, interdecadal, and quasi-century oscillations. On an interannual scale, the northern and southern slopes attain average periods of quasi 3 a (IMFn1 and IMFs1), quasi 7 a (IMFn2), and quasi 8 a (IMFs2). The cyclical temperature changes on the northern and southern slopes are roughly the same at the interannual scale, but the beginning and ending years and the amplitudes of the changes are different.

At the interdecadal scale, the temperature on the northern slope experiences periodic fluctuations of quasi 17 a (IMFn3) and 43 a (IMFn4), while the temperature on the southern slope experiences periodic fluctuations of quasi 19 a (IMFs3) and 37 a (IMFs4). The cycles on the northern and southern slopes are not very different, but the amplitudes are dissimilar. The 1859-1880 and 1925-1963 periods on the northern slope belong to the strong IMFn3 period. The trend for the southern slope is relatively flat, and 
the amplitude is significantly lower than the average amplitude from 1894-1924, which is the weaker IMFs3 period. The amplitude of IMFn3 on the northern slope is generally higher than that on the southern slope. Except for the period from the 1940s to the 1990s, the amplitude of IMFn4 on the northern slope is slightly lower than that of IMFs4 during the rest of the period. The difference in amplitude indicates that the temperature on the northern slope at the quasi-18-19 a scale is more cyclical, while that on the southern slope at the quasi-37-43 a scale is more cyclical.

On a quasi-century scale, the periods of IMFs5 and IMFn5 are similar. Except for the large fluctuations in the temperature cycle and amplitude on the southern slope from 1839-1871 and 1902-1950, the temperature change periods and amplitudes on the southern and northern slopes are similar during the remainder of the period. The trend items RESn and RESs reveal that over the past 179 years, the temperatures on the northern and southern slopes exhibit a nearly linear but actually nonlinear rising gentle - rising trend.

\subsection{Reconstructing the multiscale characteristics of the air temperature}

This paper reconstructs the interannual, interdecadal, and quasi-century scale periodic changes in the temperature in the Qinling Mountains (Figure. 4). Among these changes, the interannual temperature change is obtained by adding the first and second IMF components, the interdecadal scale temperature change is determined by adding the 3rd and 4th IMF components, and the quasi-century scale temperature change is obtained by adding the 5th IMF component and the RES trend term.

According to Figures 2 and 4 , the reconstructed interannual scale change trend can describe the fluctuation state of the original temperature sequence during the study period. The interdecadal change fully reflects the variation in the original temperature anomaly during the different periods of the climate patterns, and the quasi-century scale changes explain the general trend of the temperature changes during the study period. On an interannual scale, the temperature amplitude on the northern slope is generally higher than that on the southern slope. However, since the late 1990s, the interannual scale amplitude on the southern slope is higher than that on the northern slope. At the interdecadal scale, the amplitude on the northern slope is higher than that on the southern slope during the entire study period, and the temperature on the southern slope changes slowly. On a quasi-century scale, before 1940, the amplitude on the northern slope was higher than that on the southern slope, and the temperature change on the northern slope was more severe than that on the southern slope. After 1940, the temperature amplitude on the southern slope was higher than that on the northern slope, and the fluctuations intensified.

At the interannual and interdecadal scales, the amplitude of the temperature on the northern slope of the Qinling Mountains is generally higher than that on the southern slope. The possible reason is that the Qinling Mountains are located in the tail region of the East Asian monsoon. Hence, the northern slope area is more greatly affected by the alternation between the East Asian and northwest monsoons and the complex changes in global climate circulation. The northern slope is shaded by the Qinling Mountains, the underlying surface, including vegetation, topography and other factors, is more sensitive to climate 
changes, and vegetation growth imposes a more obvious modulating effect on the temperature. The northern slope exhibits a large temperature difference between the morning and evening and between the months. In the months with sufficient heat, the climate change is similar to that on the southern slope, but the difference is obvious in the other months. Due to many factors, the temperature amplitude on the northern slope of the Qinling Mountains is higher than that on the southern slope.

Table 2 Qinling temperature trend rate from February to April 1959-2013

\begin{tabular}{lllll}
$\begin{array}{l}\text { Propensity rate }\left({ }^{\circ} \mathrm{C} / 10\right. \\
\text { a) }\end{array}$ & $\begin{array}{l}\text { Original } \\
\text { sequence }\end{array}$ & $\begin{array}{l}\text { Interannual } \\
\text { scale }\end{array}$ & $\begin{array}{l}\text { Interdecadal } \\
\text { scale }\end{array}$ & $\begin{array}{l}\text { Quasi-century } \\
\text { scale }\end{array}$ \\
\hline Northern slope & 0.18 & 0.003 & 0.09 & 0.10 \\
\hline Southern slope & 0.13 & -0.003 & 0.04 & 0.09
\end{tabular}

Numerous studies have demonstrated that the temperature in the Qinling Mountains has been on the rise over the past 50 years (Li et al. 2018; Qi et al. 2019). A linear analysis of the reconstructed temperature changes at the different scales over the past 50 years is carried out. The early spring temperature in the Qinling Mountains has been rising over the past 50 years, which is mainly reflected at the interdecadal and quasi-century scales. The temperature growth rate on the northern slope is higher than that on the southern slope, which is mainly manifested in the dramatic changes in temperature on the northern slope on an interdecadal scale (Table 2).

The variance contribution rate constitutes the basis to evaluate the degree of influence of the frequency and amplitude of each component on the overall characteristics of the original temperature series (Bai et al. 2017). Table 3 provides the variance contribution rate of the air temperature components (IMFn and IMFs) on the southern and northern slopes of the Qinling Mountains after decomposition and calculates the correlation coefficient with the original air temperature series. The contribution rate to the interannual variance on the northern slope is $47 \%$, the decadal variance contribution rate is $31.64 \%$, and the quasicentury scale variance contribution rate is $21.36 \%$. The sum of the contribution rates to the interannual variance on the southern slope is $52 \%$, the sum of the decadal variance contribution rates is $21.22 \%$, and the sum of the quasi-century scale variance contribution rates is $26.78 \%$. Both the southern and northern slopes reveal the most significant temperature changes at the interannual scale. The difference is that the decadal contribution on the northern slope exceeds the quasi-century scale contribution, while the quasicentury scale contribution on the southern slope is greater than the decadal contribution.

Through the significance test, it is found that except for IMFn2 on the northern slope of the Qinling Mountains, which falls on the 0.05 confidence line, the other components occur above the 0.05 confidence line, and the significance test is passed. Each component on the southern slope passes the significance test and is significantly higher than that on the northern slope (Figure. 5). The test results correspond to the variance contribution rate and correlation coefficient of the original series. 
Table 3 Period, correlation coefficient and variance contribution rate of the IMFn and IMFs components of the temperature series from February-April 1835-2014 on the northern and southern slopes of the Qinling Mountains

\begin{tabular}{|c|c|c|c|c|c|c|}
\hline IMFn component & IMFn1 & IMFn2 & IMFn3 & IMFn4 & IMFn5 & RESn \\
\hline Period (a) & quasi 3 & quasi 7 & quasi 17 & quasi 42 & $\begin{array}{l}\text { quasi } 80-100 \\
\text { a }\end{array}$ & \\
\hline Correlation coefficient & $0.58^{\star \star}$ & $0.43^{\star *}$ & $0.44^{\star \star}$ & $0.54^{\star *}$ & $0.45^{\star \star}$ & $0.26^{\star \star}$ \\
\hline $\begin{array}{l}\text { Variance contribution } \\
\text { rate }(\%)\end{array}$ & 35.33 & 18.12 & 15.36 & 10.08 & 11.40 & 9.35 \\
\hline IMFs component & IMFs1 & IMFs2 & IMFs3 & IMFs4 & IMFs5 & RESs \\
\hline Period (a) & quasi 3 & quasi 8 & quasi 19 & quasi 37 & $\begin{array}{l}\text { quasi } 70-100 \\
\text { a }\end{array}$ & \\
\hline Correlation coefficient & $0.49^{\star \star}$ & $0.54^{\star *}$ & $0.49^{\star *}$ & $0.53^{\star \star}$ & $0.46^{\star \star}$ & $0.36 * \star$ \\
\hline $\begin{array}{l}\text { Variance contribution } \\
\text { rate (\%) }\end{array}$ & 24.01 & 29.95 & 8.17 & 14.31 & 14.31 & 16.46 \\
\hline
\end{tabular}

\section{** indicates $\mathrm{P}<0.01$}

Under global warming, temperatures worldwide have experienced a nonlinear and complex change process (Ji et al. 2014; Bai et al. 2014; Wang and Li 2011), which suggests that the nonlinear and complex process of the temperature changes in the Qinling Mountains is not an accidental phenomenon but an inherent reflection of the climate system. There occurs a certain correlation with the climate cycle changes in other regions. In this paper, the quasi-period of the temperature in the Qinling Mountains is compared to the multiscale periods of the May-July temperature decomposed via EEMD in central Qinling (Hu et al. 2018), the early summer temperature in the northern part of the Western Sichuan Plateau (Li et al. 2015), and the average temperature over the past 100 years in China (Tang and Ren 2005). Several change patterns exhibit similar quasi-periods, which are the most obvious at the interannual scale and slightly different on the interdecadal and quasi-century scales (Table 4). Although the periods of the temperature fluctuations in the various regions are similar at the interannual scale, the correlation between the interannual temperature fluctuations in the various regions is low due to the frequent periodic conversions and complex fluctuations at the high-frequency (smaller) scale. Comparing the reconstructed interdecadal and quasi-century scale cycles, it is found that, with the exception of the quasi-century scale average temperature over the past 100 years in China, there exists a significant positive correlation with the Qinling temperature in this paper at the corresponding time scale (Table 4), which indicates a better synchronization trend. The insignificant quasi-century scale correlation with the average temperature in China over the past 100 years may be attributed to the short temperature series 
over the past 100 years and the fewer quasi-century scale fluctuations, which reflects the changes above the quasi-century scale. In contrast, since the 1950 s, the warming trend thereafter is similar to that of the other series.

Figure 6 shows the comparison results of the reconstructed Qinling area temperature in this paper to the three sets of temperature series at the interdecadal and quasi-century scales. On an interdecadal scale, several series reveal similar fluctuation trends. On a quasi-century scale, the temperature trend in the Qinling region decomposed in this paper attains the highest correlation with the temperature fluctuation trend in central Qinling from May to July, indicating that the periodicity of the temperature in the Qinling region from February to April is representative for the study of the periodicity of the temperature in the region during other periods. Since 1950, the quasi-century-scale fluctuation trends of the four series are almost the same, revealing a trend of falling first and then rising. This trend has been confirmed by many scholars (Jiang et al. 2013; Duan et al. 2014), indicating that the quasi-century-scale changes in the temperature in the Qinling area are similar to those in the other regions. The similarities between the above regions further verify that the reconstructed quasi-century scale changes can better reflect historical-future climate trends than can traditional linear changes. In addition, the temperature cycle in the Qinling Mountains was compared to that in Northwest China, as decomposed by Chen et al. through the EEMD method over the past 100 years, and that in the Northern Hemisphere and the Beijing area over the past two thousand years, as decomposed by Yang Zhou et al (Table 4) (Chen et al. 2017; Shi Feng et al. 2015). Although there were slight differences, the average periods of quasi 3 a, quasi 7-8 a, quasi 1719 a, quasi 37-43 a, and quasi 70-100 a with the temperature in the Qinling Mountains were also observed in the northwestern region of China, Beijing and the Northern Hemisphere. This demonstrates that the average periodic change in the temperature decomposed in this paper can more truly reflect the characteristics of the temperature in the region at the different time scales, and this feature exhibits a certain spatial representativeness.

Table 4 Multiscale periods of the temperature in the other regions and their correlation at the different scales in the Qinling area 


\begin{tabular}{|c|c|c|c|c|c|c|}
\hline Area & $\begin{array}{l}\text { Central } \\
\text { area of } \\
\text { Qinling (Hu } \\
\text { et al. 2018) }\end{array}$ & $\begin{array}{l}\text { Western } \\
\text { Sichuan } \\
\text { Plateau (Li } \\
\text { et al. 2015) }\end{array}$ & $\begin{array}{l}\text { China } \\
\text { (Tang } \\
\text { and Ren } \\
\text { 2005) }\end{array}$ & $\begin{array}{l}\text { Northwestern } \\
\text { region (Chen } \\
\text { et al. 2017) }\end{array}$ & $\begin{array}{l}\text { Beijing } \\
\text { area (Shi } \\
\text { et al. } \\
2015)\end{array}$ & $\begin{array}{l}\text { Northern } \\
\text { Hemisphere } \\
\text { (Shi et al. } \\
\text { 2015) }\end{array}$ \\
\hline Time span & $\begin{array}{l}1814- \\
2007\end{array}$ & $1854-2010$ & $\begin{array}{l}1905- \\
2009\end{array}$ & $1901-2013$ & $1-1979$ & $1-1979$ \\
\hline IMF1 & quasi 3 a & quasi 3 a & quasi 3 a & quasi 2-3 a & quasi 3 a & quasi 6 a \\
\hline IMF2 & quasi 8 a & quasi 6 a & quasi 8 a & quasi 6-7 a & quasi 6 a & quasi 11 a \\
\hline IMF3 & quasi $20 \mathrm{a}$ & quasi $14 \mathrm{a}$ & $\begin{array}{l}\text { quasi } 18 \\
\text { a }\end{array}$ & quasi $14 \mathrm{a}$ & $\begin{array}{l}\text { quasi } 11 \\
\text { a }\end{array}$ & quasi 21 a \\
\hline IMF4 & quasi 39 a & quasi 40 a & $\begin{array}{l}\text { quasi } 63 \\
\text { a }\end{array}$ & quasi 20 a & $\begin{array}{l}\text { quasi } 21 \\
\text { a }\end{array}$ & quasi 43 a \\
\hline IMF5 & quasi $71 \mathrm{a}$ & quasi 68 a & $\begin{array}{l}\text { quasi } 105 \\
\mathrm{a}\end{array}$ & quasi 70 a & $\begin{array}{l}\text { quasi } 42 \\
\text { a }\end{array}$ & quasi 86 a \\
\hline IMF6 & quasi 84 a & - & - & - & $\begin{array}{l}\text { quasi } 80 \\
\text { a }\end{array}$ & quasi 247 a \\
\hline IMF7 & - & - & - & - & $\begin{array}{l}\text { quasi } 166 \\
\text { a }\end{array}$ & quasi $914 \mathrm{a}$ \\
\hline IMF8 & - & - & - & - & $\begin{array}{l}\text { quasi } 459 \\
\text { a }\end{array}$ & - \\
\hline $\begin{array}{l}\text { Interdecadal } \\
\text { scale }\end{array}$ & $0.22^{\star \star}$ & $0.18 *$ & 0.31 ** & & & \\
\hline $\begin{array}{l}\text { Quasi- } \\
\text { century } \\
\text { scale }\end{array}$ & $0.80 * *$ & $0.37^{\star \star}$ & 0.13 & & & \\
\hline
\end{tabular}

\section{* indicates $\mathrm{P}<0.05 ;$ ** indicates $\mathrm{P}<0.01$}

\subsection{Multiscale response of the early spring Qinling temperature to the climate signals}

The multiscale temperature oscillation in the Qinling Mountains not only reflects the nonlinear feedback within the climate system but also reflects the periodic evolution of the climate system under external forcing. To identify the response of the Qinling Mountain temperature to ocean oscillations and atmospheric circulation at different time scales based on the periodic changes in the early spring temperature and to provide a basis for the prediction of regional climate evolution, this paper selects seven climate signals to study the response of the multiscale periodic changes in the early spring temperature in the Qinling Mountains to global climate change (Table 1). Through the Pearson correlation analysis method, the time series of the average value of each climate signal from February to April in the current year and the monthly value in the previous year from May to April in the current year were correlated with the early spring temperature in the Qinling Mountains (considering that the response of the inland air temperature to the climate signals may exhibit a time lag), thereby selecting those months 
with significant correlations. Through the EEMD method, the time series of the months with significant correlations between the climate signals are decomposed at multiple scales, and the bivariate correlation between the IMF components of the climate signals and the IMF components of the Qinling early spring temperature with similar periods is established to study the response of the Qinling area temperature to the climate signals at the different time scales.

Table 5 indicates that the Qinling average temperature from February to April attains the strongest correlation with AMO during the same period (0.33), and AMO attains a significant correlation with the Qinling temperature in most months. There exists a significant positive correlation between the Niño 3.4 regional sea temperature in May of the previous year and the average temperature in Qinling from February to April. Moreover, SOI achieves a significant negative correlation in May and September of the previous year, with the strongest correlation in May of the previous year. NP attains a significant negative correlation with the Qinling temperature in May of the previous year. The NAO index reaches a significant positive correlation with the Qinling temperature in December of the previous year. PDO and GATA exhibit no significant correlation with the Qinling temperature in any month.

Table 5 Correlation between the temperature and climate signals in Qinling from February to April

\begin{tabular}{llllllll} 
Month & Nino3.4 & SOI & NP & NAO & AMO & PDO & GATA \\
\hline $2-4$ & 0.05 & 0.00 & 0.08 & 0.02 & $0.33^{\star \star}$ & 0.01 & 0.06 \\
\hline 1 & 0.09 & -0.05 & 0.09 & 0.12 & $0.31^{\star \star}$ & 0.06 & 0.03 \\
\hline 2 & 0.05 & -0.05 & 0.13 & -0.04 & $0.29^{\star \star}$ & 0.03 & 0.05 \\
\hline 3 & 0.03 & 0.04 & 0.11 & -0.04 & $0.30^{\star \star}$ & -0.04 & 0.04 \\
\hline 4. & 0.06 & 0.00 & -0.14 & 0.13 & $0.27 \star \star$ & 0.03 & 0.08 \\
\hline P5 & $0.16^{\star}$ & $-0.21^{\star}$ & $-0.25^{\star \star}$ & 0.07 & $0.32^{\star \star}$ & 0.08 & 0.06 \\
\hline P6 & 0.15 & -0.11 & -0.11 & -0.11 & $0.26^{\star \star}$ & 0.06 & 0.08 \\
\hline P7 & 0.13 & -0.02 & -0.10 & -0.07 & $0.22^{\star \star}$ & 0.13 & 0.09 \\
\hline P8 & 0.12 & -0.13 & 0.09 & -0.03 & $0.24 * \star$ & 0.14 & 0.09 \\
\hline P9 & 0.11 & $-0.17 *$ & 0.04 & -0.08 & $0.17 *$ & 0.08 & 0.11 \\
\hline P10 & 0.11 & -0.04 & -0.01 & 0.00 & 0.14 & 0.04 & 0.16 \\
\hline P11 & 0.10 & -0.13 & 0.00 & 0.07 & 0.16 & 0.00 & 0.11 \\
\hline P12 & 0.09 & -0.05 & -0.03 & $0.16 *$ & $0.24 * \star$ & -0.01 & 0.02
\end{tabular}

$P$ indicates the month of the previous year, * indicates $P<0.05$, and ** indicates $P<0.01$ 
Table 6 reveals the multiscale periodic oscillations during the period when the climate signals achieve the strongest correlation with the Qinling temperature. The quasi-period of the temperature attains similar periods for most climate signals. Further analysis of the correlation between the temperature and various climate signals at the different time scales (Table 7) demonstrates that although each index attains a significant correlation with the Qinling temperature, the degree of the temperature response to the various climate signals varies between the different time scales. At the interannual cycle scale, the Qinling early spring temperature at the quasi 3 a scale only attains a significant positive correlation with the sea temperature of the previous May in the Niño 3.4 area, and a good response to GATA is observed. At the quasi 6 a scale, the Qinling early spring temperature is significantly negatively correlated with SOI and significantly positively correlated with Niño 3.4 and NAO. Among these climate signals, the correlation with NAO is the highest, reaching 0.40 . On an interdecadal cycle scale, the quasi 17-19a scale is only significantly correlated with AMO. At the quasi 37-43a scale, the number of climatic factors that are significantly related to the Qinling early spring temperature increases. All climate signals, except NAO and $\mathrm{NP}$, attain a significant correlation with the Qinling early spring temperature. Among these climate signals, SOI and Niño 3.4 are negatively correlated with the Qinling temperature. Niño 3.4 attains a significant positive correlation with the Qinling temperature at the other scales, so the negative correlation at this scale also reduces the correlation with Niño 3.4 across the entire time scale. At the quasi-century scale, there exists a significant correlation between the Qinling temperature and the various climate signals. The response to GATA is the strongest among the two scales (0.50), indicating that the early spring temperature in the Qinling Mountains exhibits a greater response to global temperature fluctuations under large-scale periodic changes than that under small-scale changes. The possible reason is that the smallscale periodic changes in the temperature are affected not only by global climate change but also by other factors (such as changes in topography, clouds, aerosols, sunspots, and solar irradiance). The changes in these factors are complex and yield a more direct impact on the local temperature at the interannual scale, leading to an insignificant response to large-scale climate circulation on a smaller scale. In contrast, the temperature in the Qinling Mountains on a larger scale exerts an impact on global climate change, and the response is more obvious and positive. IMF2 and IMF3 of the Qinling early spring temperature are negatively correlated with the global average early spring temperature or an important influencing factor causing these two components to be uncorrelated during the entire study period. This further indicates that the Qinling early spring temperature exhibits a unique change cycle at this scale.

Table 6 Multiscale cycles of the various climate signal 


\begin{tabular}{llllllll} 
Cycle (a) & SOI & Nino3.4 & PDO & AMO & NAO & NP & GATA \\
& $($ P5 $)$ & $($ P5 $)$ & $(2-4)$ & $(2-4)$ & $(\mathrm{P} 12)$ & $(P 5)$ & $(2-4)$ \\
\hline IMF1 & 3.08 & 3.12 & 3.07 & 2.98 & 2.71 & 2.98 & 2.88 \\
\hline IMF2 & 6.72 & 5.69 & 6.67 & 6.37 & 5.60 & 6.97 & 5.95 \\
\hline IMF3 & 14.10 & 13.83 & 15.24 & 14.74 & 12.34 & 13.55 & 12.77 \\
\hline IMF4 & 32.89 & 29.00 & 35.56 & 35.00 & 27.54 & 32.86 & 34.00 \\
\hline IMF5 & 49.33 & 79.50 & 65.00 & 70.00 & 71.60 & 57.50 & 72.00
\end{tabular}

Although the Qinling early spring temperature and the Niño 3.4 regional sea temperature were only significantly correlated in May of the previous year, analysis of the correlation between the combined months indicates that there remains a significant correlation between the April-July average sea temperature and the Qinling early spring temperature (0.16). The change in sea temperature in the Niño 3.4 area is an important indicator for the assessment of the ENSO phenomenon and an important indicator of the mutual modulation of the atmosphere and ocean systems. ENSO usually causes changes in atmospheric circulation and thus affects climate anomalies in certain parts of the world on an interannual scale (Timilsena et al. 2008; Chen et al. 2013; Zhu et al. 2007). This affects the temperature changes in northern China through Asian monsoon activity (Cai and Liu 2013; Raspopov et al. 2004), and the early spring temperature in the Qinling Mountains responds well to Niño 3.4 on multiple scales, indicating that this area may be affected by the multiscale effects of ENSO periodic activities (Jiang and Li 2011).

Table 7 Correlation between the temperature in Qinling and the climate signal components

\begin{tabular}{llllllll} 
& SOI & Nino3.4 & PDO & AMO & NAO & NP & GATA \\
\hline IMF1 & -0.15 & $0.23^{\star \star}$ & 0.11 & -0.11 & 0.08 & -0.08 & $0.30^{\star \star}$ \\
\hline IMF2 & $-0.17^{\star \star}$ & $0.17^{\star \star}$ & 0.03 & -0.01 & $0.40^{\star \star}$ & -0.09 & -0.10 \\
\hline IMF3 & 0.09 & -0.13 & -0.01 & $0.41^{\star \star}$ & 0.07 & -0.01 & -0.14 \\
\hline IMF4 & $-0.37^{\star \star}$ & $-0.33^{\star \star}$ & $0.19^{\star}$ & $0.39^{\star \star}$ & 0.01 & 0.14 & $0.23^{\star \star}$ \\
\hline IMF5 & $-0.26^{\star \star}$ & $0.19^{\star}$ & $-0.25^{\star \star}$ & $0.40^{\star \star}$ & $0.49^{\star \star}$ & $-0.20^{\star}$ & $0.50^{\star \star}$ \\
\hline RES & $-0.78^{\star \star}$ & $0.99^{\star \star}$ & $0.74^{\star *}$ & -0.01 & $0.27^{\star \star}$ & $-0.35^{\star \star}$ & $0.99^{\star \star}$
\end{tabular}

* indicates $\mathrm{P}<0.05 ;$ ** indicates $\mathrm{P}<0.01$ 
Overall, as shown in Figure 7, compared to the other climate signals (such as NAO, SOI, NP, and PDO), AMO achieves a closer relationship with the changes in the Qinling early spring temperature. Moreover, this relationship is reflected at the different time scales, which is consistent with the conclusion that the relationship between $\mathrm{AMO}$ and the temperature in China is stronger than that with the other climate signals, as reported by Wang et al. (Wang et al. 2013). This stable relationship between these two variables may be one of the main influencing factors of the multiscale change in the early spring temperature in Qinling. There are many possible reasons for the mechanism by which AMO affects the temperature. Tung et al. proposed that the multidecadal temperature oscillation is a change mode reflected by AMO that affects the internal changes in the climate system (Ka-Kit and Zhou 2013). Lu et al. acknowledged that AMO affects the multidecadal changes in the climate of the Eurasian continent by causing a feedback mechanism of the atmosphere and ocean in the western Pacific (Lu et al. 2006). In addition, studies have found that most areas in China experience a warm winter when the AMO phenomenon occurs in the positive (warm) phase (Qu et al. 2006). This conclusion has also been confirmed by different scientists. The interdecadal variation in AMO and the East Asian monsoon still yields an obvious modulation effect. When AMO occurs in the positive phase, the East Asian summer monsoon will increase, the winter monsoon will weaken, and the cold phase will be reversed ( $\mathrm{Li}$ et al. 2009). Therefore, the change in AMO at the interdecadal scale may be an important factor leading to the increase in the early spring temperature in the Qinling area.

Table 7 demonstrates that at the different time scales, the relationship between AMO and the Qinling early spring temperature is not unique. These two variables are positively correlated on certain scales and negatively correlated on other scales. During the entire study period, the correlation between the original temperature series and the AMO index was lower than that with the decomposed components. It may be that the positive correlation on certain scales may be offset by the negative correlation at the other scales. Alternatively, within the same IMF, the positive correlation during certain periods may be offset by the negative correlation during other periods. Figure 7 shows that the phase changes of the air temperature and $\mathrm{AMO}$ at the different time scales are the same during certain periods but are the opposite during the other periods. For example, IMF2 exhibits the opposite phase of the temperature and AMO from 1940-1970, and IMF5 exhibits the same phase from 1920-1958. Figure 7 shows that there occurs an alternating phenomenon in the correlation between the air temperature and AMO for each IMF component. To analyze the relationship between these two variables, it is necessary to conduct a dynamic correlation analysis of the region.

Traditional correlation analysis indicates that the longer the time span is, the more unstable factors occur, and the temperature and climate signals experience nonlinear changes, which makes it difficult to accurately characterize the correlation. To quantify the relationship between these two aspects locally, dynamic correlation analysis should be carried out (Rodó et al. 2006; Scafetta N 2014). When performing dynamic correlation analysis to study the relationship between two time series with multiscale features, it is necessary to perform local correlation analysis by selecting an appropriate sliding window. 
TDIC analysis is performed between the IMFs components of the two time series with a similar periodicity, and a TDIC analysis chart is generated by adaptively selecting the sliding window size (to ensure the stability of the sliding window, rather than the stability of the entire time domain). The first four IMF components with a clear significance were selected with the TDIC method to analyze the correlation between AMO and air temperature (Figure. 8). The abscissa in the figure represents the year, and the ordinate represents the size of the sliding window for these two data columns.

Figure 8 shows that $\mathrm{AMO}$ attains a correlation with alternating positive and negative air temperatures in the IMF1 component, and a significant negative correlation is obtained from 1940-1975, while the IMF2 component achieves no significant correlation in most years. Except for the two ends of the sliding window, the IMF3 and IMF4 components are significantly positively correlated throughout the entire study period. AMO and the temperature also attain a significant correlation at the quasi 3 a scale, but this correlation varies over time, which leads to a lower correlation during the entire study period. The reason for this reversal is currently unclear. This may be attributed to the many years of lead-lag correlation between the temperature and climate signals and the complexity of the internal interaction between the ocean and the atmosphere.

The terrain of the Qinling Mountains is complex, and the temperature response to the AMO climate signal may be different in the various regions. Figure 9 shows the spatial correlation between the temperature and AMO at various scales. Under the IMF1 component, there occurs no significant correlation between the temperature and AMO in any region. Under the IMF2 component, the response of the temperature in the west Qinling area is more significant, while under the IMF3 and IMF4 components, the temperature in most of the Qinling Mountains attains a significant correlation with AMO. The trend item achieves a negative correlation between the air temperature and $\mathrm{AMO}$ in most high-altitude areas and a positive correlation at lower altitudes. This suggests that the early spring temperature in the Qinling Mountains responds differently to the AMO climate signal in the various regions at the different time scales.

\section{Conclusion}

This paper employs EEMD to analyze the multiscale temporal and spatial characteristics of temperature anomalies from February to April, 1835 to 2013, on the northern and southern slopes of the Qinling Mountains and examines the response of the temperature to climate signals on different time scales. The main conclusions are as follows:

Over the past 179 years, the early spring temperature on the northern and southern slopes of the Qinling Mountains exhibits a nonlinear increasing trend and reveals significant characteristics at the different time scales. The northern slope indicates average periods of quasi 3 a, quasi 6 a, quasi 18 a, quasi 42 a, and quasi 80-100 a, and the southern slope indicates average periods of quasi 3 a, quasi 7 a, quasi 19 a, quasi $37 \mathrm{a}$, and quasi $70-100 \mathrm{a}$. The contribution at the various scales to the increase in early spring temperature on the northern slope of the Qinling Mountains follows the order of interannual scale > 
interdecadal scale > quasi-century scale changes. On the southern slope, the order is interannual scale > quasi-century scale $>$ interdecadal scale changes.

The reconstructed interannual temperature changes effectively describe the fluctuations in the original temperature sequence during the study period. The interdecadal changes reflect the changes in climate patterns during the different historical periods. The quasi-century scale changes reflect the overall trend of climate change on a large scale. The early spring temperature on the northern slope of the Qinling Mountains attains a higher amplitude than that on the southern slope at the interannual and interdecadal scales most of the time. On a quasi-century scale, the amplitude is higher than that on the southern slope before 1940, and vice versa thereafter. Over the past 50 years, the increase in the early spring temperature on the northern slope of the Qinling Mountains was larger than that on the southern slope, mainly due to interdecadal temperature fluctuations.

The early spring temperature in the Qinling Mountains responds differently to the climate signals at the different time scales and various time ranges. There exists a significant correlation between the temperature and AMO during the same period and a significant correlation with SOI in May and with Niño 3.4, NP, and NAO in December, lagging one year. On an interannual scale, the temperature attains the most significant response to the May SST in the Niño 3.4 area. At the interdecadal scale, the response is the strongest for AMO. At the quasi-century scale, the responses of the various climate signals are significant, and the correlation is generally higher than that at the interannual and interdecadal scales. The early spring temperature in the Qinling Mountains achieves a stronger synchronization with global climate change on a larger scale. The weaker correlation between the temperature and AMO at the interannual scale is attributed to the different correlations during the various periods, and the positive and negative correlations cancel each other during the entire study period. In terms of spatial changes, these two aspects reveal that the larger the scale, the wider the response range is, and there are differences between the different altitudes.

In addition, it should be noted that since the temperature data selected in this paper comprise an average sequence from February to April, although the sequence is related to the trend of annual average temperature changes, there are certain differences. Hence, the data cannot represent continuous temperature changes. Therefore, the possible lead-lag correlations between the temperature and climate signals at the different time scales, such as the monthly or interdecadal time scales, were not analyzed. Finally, since the long-term temperature and climate signals are reconstructed from proxy data, there exists a certain error, which may also be one of the factors that cause the correlation between these two variables to be insignificant, which should be further verified with more comprehensive data.

\section{Declarations}

\section{Acknowledgements}

All authors contributed to the study conception and design. Material preparation, data collection and analysis were performed by Chenhua Zhang, Jiachuan Wang, Shuheng Li and Li Hou. All authors read 
and approved the final manuscript.

The authors are grateful to the editors and anonymous reviewers for their useful comments and suggestions.

Funding: This study has been funded by a General Program from the Natural Science Foundation of Shaanxi Province (no. 2014JQ5172), the Open Fund Project of the State Key Laboratory of Loess and Quaternary Geology(no.SKLLQG1611), and the National Forestry Public Welfare Industry Scientific Research Project of China (no. 201304309).

Conflicts of interest/Competing interests: Non-financial interests.

Availability of data and material: All data generated or analysed during this study are included in this published article [and its supplementary information files].

Code availability: Not applicable.

Authors' contributions: Chenhua Zhang and Jiachuan Wang are co-worked and have equal contributions.

Ethics approval: Approval.

Consent to participate: YES.

Consent for publication: YES.

\section{References}

1. Adrsh S (2017) Unveiling the multiscale teleconnection between Pacific Decadal Oscillation and global surface temperature using time-dependent intrinsic correlation analysis. International Journal of Climatology 37(1): 548-558. https://doi.org/10.1002/joc.4713

2. Agbazo MN, N'Gobi, GK et al (2021) Assessing Nonlinear Dynamics and Trends in Precipitation by Ensemble Empirical Mode Decomposition (EEMD) and Fractal Approach in Benin Republic (West Africa). Complexity. https://doi.org/10.1155/2021/3689397

3. Bai HY, Ma XP, Gao X et al (2012) Variations in January Temperature and $0^{\circ} \mathrm{C}$ Isothermal Curve in Qinling Mountains Based on DEM. Acta Geographica Sinica 67(11): 1443-1450 (in Chinese)

4. Bai L, Chen ZS, Xu JH (2014) The regional features of temperature variation trends over Xinjiang in China by the ensemble empirical mode decomposition method. International Journal of Climatology 35(11): 3229-3237. https://doi.org/10.1002/joc.4202

5. Bai L, Liu ZH, Chen ZS et al (2017) Runoff nonlinear variation and responses to climate fluctuation in the headwater region of the Kaidu River. Resources Science 39(8): 1511-1521 (in Chinese)

6. Cai QF, Liu Y (2013) Climatic response of Chinese pine and PDSI variability in the middle;Taihang Mountains, north China since 1873. Trees 27(2): 419-427. https://doi.org/10.1007/s00468-012-0812- 
7. Chen F, Yuan YJ, Wei WS et al (2013) Tree-ring based temperature reconstruction for the west Qinling Mountains (China): linkages to the High Asia, solar activity and Pacific-Atlantic Ocean.

Geochronometria 41(3): 234-244. https://doi.org/10.2478/s13386-013-0159-9

8. Chen W, Lan XQ, Wang L et al (2013) The combined effects of the ENSO and the Arctic Oscillation on the winter climate anomalies in East Asia. Chinese Science Bulletin 58(8): 634-641 (in Chinese)

9. Chen XY, Zhao HW, Huang NE (2010) The Time-Dependent Intrinsic Correlation Based on the Empirical Mode Decomposition. Advances in Adaptive Data Analysis 2(2): 233-265. https://doi.org/10.1142/S1793536910000471

10. Chen ZS, Chen YN, Bai L et al (2017) Multiscale evolution of surface air temperature in the arid region of Northwest China and its linkages to ocean oscillations. Theoretical \& Applied Climatology 128(3-4): 945-958

11. Duan LY, Ding YH, Ren Y (2014) Multiscale Examination on the Temperature and Precipitation Series in Tianjin during 1921-2010. Climatic and Environmental Research 19(4): 515-522. https://doi.org/10.1007/s00704-016-1752-7

12. Garfin GM, Hughes MK, Liu Y et al (2005) Exploratory Temperature and Precipitation Reconstructions from the Qinling Mountains, North-Central China. Tree-Ring Research 61(2): 59-72. https://doi.org/10.3959/1536-1098-61.2.59

13. Hou L, Li SH, Chen L et al (2017) Reconstruction of the historical temperature from February to April of the Qinling Mountains in recent 200 years. Geographical Research 36(8): 1428-1442 (in Chinese)

14. Hu YF, Bao G, Liu N et al (2018) May-July mean minimum temperature variability in the mid-Qinling Mountains, central China, since 1814 CE. Quaternary International 476(20): 102-109. https://doi.org/10.1016/j.quaint.2018.02.012

15. Ji F, Wu ZH, Huang JP et al (2014) Evolution of land surface air temperature trend. Nature Climate Change 4(6): 462-466. https://doi.org/10.1038/nclimate2223

16. Jia YQ, Zhang B, Zhang YZ et al (2017) Correlation analysis of variation of extreme temperature events and El Niño Southern Oscillation(ENSO) in Yangtze River Delta region during 1960-2014. Acta Ecologica Sinica 37(19): 6402-6414

17. Jiang C, Wang F, Liu SJ et al (2013) Evaporation paradox in the northern and southern regions of the Qinling Mountains. Acta Ecologica Sinica 33(3): 844-855 (in Chinese)

18. Jiang XW, Li YQ (2011) Spatio-temporal variability of winter temperature and precipitation in Southwest China. Journal of Geographical Sciences 21(2): 250-262. https://doi.org/10.1007/s11442-011-0842-9

19. Ka-Kit T, Zhou JS (2013) Using data to attribute episodes of warming and cooling in instrumental records. Proceedings of the National Academy of Sciences of the United States of America 110(6): 2058-2063. https://doi.org/10.1073/pnas.1212471110

20. Knight JR, Folland CK, Scaife AA (2006) Climate impacts of the Atlantic Multidecadal Oscillation. Geophysical Research Letters 33(17):3214-3221. https://doi.org/10.1029/2006GL026242 
21. Lei XY (1999) Loess-Paleosol Sequences on the Eastern Qinling Mts. During the Last 0.6Ma. Marine Geology \& Quaternary Geology 19(1): 3-5 (in Chinese)

22. Li JJ, Shao XM, Li YY et al (2015) The Relationship Between Early Summer Air Temperature and the Global Sea Surface Temperature in the North of Western Sichuan Plateau from 1854 to 2010. Journal of Desert Research 35(4): 1024-1035 (in Chinese)

23. Li SL, Jing YY, Luo FF (2015) The potential connection between China surface air temperature and the Atlantic Multidecadal Oscillation (AMO) in the Pre-industrial Period. Science China Earth Sciences 58(10): 1814-1826. https://doi.org/10.1007/s11430-015-5091-9

24. Li SL, Wang YM, Gao YQ (2009) A Review of the Researches on the Atlantic Multidecadal Oscillation(AMO) and Its Climate Influence. Journal of Nanjing Institute of Meteorology 32(3): 458465 (in Chinese)

25. Li SS, Lu JY, Yan JP et al (2018) Spatiotemporal variability of temperature in northern and southern Qinling Mountains and its influence on climatic boundary. Acta Geographica Sinica 73(1): 13-24 (in Chinese)

26. Li SS, Yan JP, Wan J (2012) The Characteristics of Temperature Change in Qinling Mountains. Scientia Geographica Sinica 32(7): 853-858 (in Chinese)

27. Lu RY, Dong BW, Hui D (2006) Impact of the Atlantic Multidecadal Oscillation on the Asian summer monsoon. Geophysical Research Letters 33(24): 194-199. https://doi.org/10.1029/2006GL027655

28. Ma LM, Liu Y, An ZS (2001) ENSO Events from Tree-Ring Width in Qinling Mountain. Marine Geology \& Quaternary Geology 21(3): 93-98 (in Chinese)

29. Mann ME, Steinman BA, Miller SK (2014) On Forced Temperature Changes, Internal Variability and the AMO. Geophysical Research Letters 41(9): 3211-3219. https://doi.org/10.1002/2014GL059233

30. Qi GZ, Bai HY, Meng Q et al (2019) Climate Change in the Qinling Mountains in Spring during 19592018. Arid Zone Research 36(5): 1079-1091 (in Chinese)

31. Qu JH, Jiang ZH, Tan GR et al (2006) Relation between Interannual, Interdecadal Variability of SST in North Atlantic in Winter and Air Temperature in China. Scientic Geographica Sinica 26(5): 5557-5563 (in Chinese)

32. Raspopov OM, Dergachev VA, Kolström T (2004) Hale Cyclicity of Solar Activity and Its Relation to Climate Variability. Solar Physics 224(1-2): 455-463. https://doi.org/10.1007/s11207-005-5251-8

33. Rodó X, Rodríguez-Arias M-à (2006) A new method to detect transitory signatures and local time/space variability structures in the climate system: the scale-dependent correlation analysis. Climate Dynamics 27(5): 441-458. https://doi.org/10.1007/s00382-005-0106-4

34. Scafetta N (2014) Multi-scale dynamical analysis (MSDA) of sea level records versus PDO, AMO, and NAO indexes. Climate Dynamics 43(1-2): 175-192. https://doi.org/10.1007/s00382-013-1771-3

35. Shi F, Yang B, Feng J et al (2015) Reconstruction of The Northern Hemisphere Annual Temperature Change over The Common Era Derived from Tree Rings. Quaternary Sciences 35(5): 1051-1063 (in Chinese) 
36. Tang GL, Ren GY (2005) Reanalysis of Surface Air Temperature Change of the Last 100 Years over China. Climatic and Environmental Research 10(4): 791-798 (in Chinese)

37. Tian QH, Zhou XJ, Liu Y et al (2011) Historical Late-Spring-To-Early-Summer Temperature at Qinling Mountain Range laferred from Multi-Site Tree-Ring Chronologies, and Their Relationship with Northern Hemisphere Sea Surface Temperature. Quaternary Sciences 31(5): 864-872 (in Chinese)

38. Timilsena J, Piechota T, Tootle G et al (2008) Associations of interdecadal/interannual climate variability and long-term colorado river basin streamflow. Journal of Hydrology 365(3): 289-301. https://doi.org/10.1016/j.jhydrol.2008.11.035

39. Wang B, Li XD (2011) Multi-Scale Fluctuation of European Temperature Revealed by EEMD Analysis. Acta Scientiarum Naturalium Universitatis Pekinensis 47(4): 627-635 (in Chinese)

40. Wang JL, Yang B, Zhao Y et al (2013) The relationship between the Atlantic Multidecadal Oscillation and temperature variability in China during the last millennium. Journal of Quaternary Science 28(7): 653-658. https://doi.org/10.1002/jqs.2658

41. Wang T, Yang MH, Yan SJ et al (2021) Effects of Temperature and Precipitation on Spatiotemporal Variations of Net Primary Productivity in the Qinling Mountains, China. Polish Journal of Environmental Studies 30(1): 409-422. https://doi.org/10.15244/pjoes/122839

42. Wei FY (1999) Modern climate statistics diagnosis and prediction technology.Beijing: Meteorological Press (in Chinese)

43. Wu ZH, Huang NE (2004) A Study of the Characteristics of White Noise Using the Empirical Mode Decomposition Method. Proceedings Mathematical Physical \& Engineering Sciences 460(2046): 1597-1611. https://doi.org/10.1098/rspa.2003.1221

44. Wu ZH, Huang NE (2005) Statistical Significance Test of Intrinsic Mode Functions. Advances in Adaptive Data Analysis 42(5): 107-127

45. Wu ZH, Huang NE (2009) Ensemble Empirical Mode Decomposition: A Noise-Assisted Data Analysis Method. Advances in Adaptive Data Analysis 1(1): 1-41.

46. Wyatt MG, Curry JA (2014) Role for Eurasian Arctic shelf sea ice in a secularly varying hemispheric climate signal during the 20th century. Climate Dynamics 42(9-10): 2763-2782. https://doi.org/10.1007/s00382-013-1950-2

47. Xu M, Xu HM, Ma J et al (2021) Impact of Atlantic multidecadal oscillation on interannual relationship between ENSO and East Asian early summer monsoon. International Journal of Climatology 41(4): 2860-2877. https://doi.org/10.1002/joc.6994

48. Xue CF, Hou W, Zhao JH et al (2013) The application of ensemble empirical mode decomposition method in multiscale analysis of region precipitation and its response to the climate change. Acta Physica Sinica 62(10): 504-511 (in Chinese)

49. Yan JP, Zheng Y (2001) A comparative study on environmental change response over the northern and the southern regions of the Qinling Mountains. Geographical Research 20(5): 576-582 (in Chinese) 
50. Zhang CN, Wang HY, Liu HY et al (2015) Climatic and Environmental Changes Occurring during the Last 5520 Years on Alpine Belt of Taibai Mountain: the Records of a Few Proxies of Sediments from Foye Chi and Their Interpretations. Acta Scientiarum Naturalium Universitatis Pekinensis 51(6): 1091-1101 (in Chinese)

51. Zhang Y, Bai HY, Zhou K et al (2018) Spatial variation of extreme temperature change on southern and northern slopes of Shaanxi section in Qinling Mountains during 1960-2013. Acta Geographica Sinica 73(7): 1296-1308 (in Chinese)

52. Zhou Q, Bian JJ, Zheng JY (2011) Variation of Air Temperature and Thermal Resources in the Northern and Southern Regions of the Qinling Mountains from 1951 to 2009. Acta Geographica Sinica 66(9): 1211-1218 (in Chinese)

53. Zhu YM, Yang XQ, Chen XY et al (2007) Interdecadal Variation of The Relationship Between ENSO and Summer Interannual Climate Variability in China. Journal of Tropical Meteorology 23(2): 105116 (in Chinese)

\section{Figures}

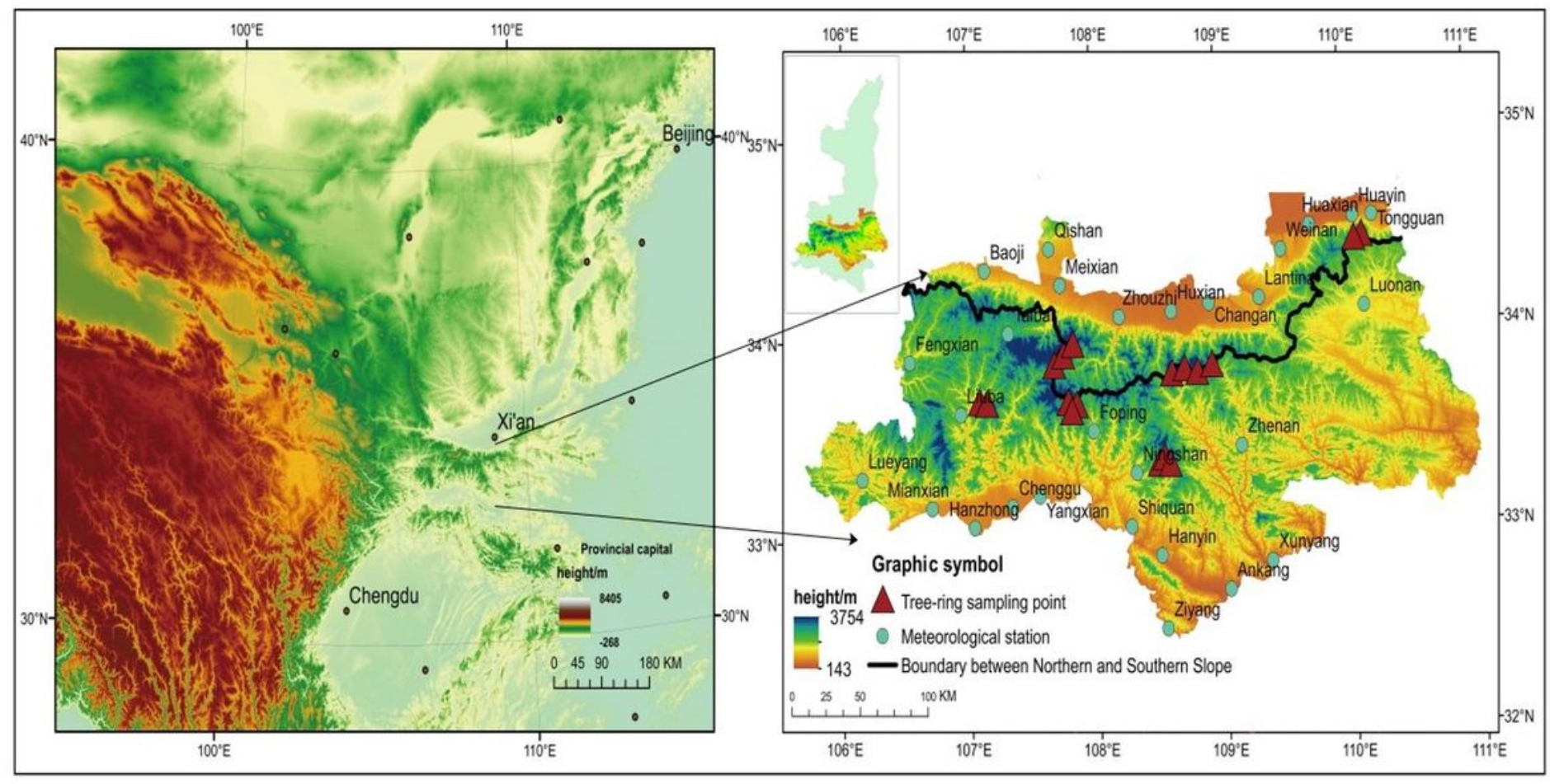

\section{Figure 1}

Distribution of the meteorological stations and tree-ring sampling sites in the Qinling Area 


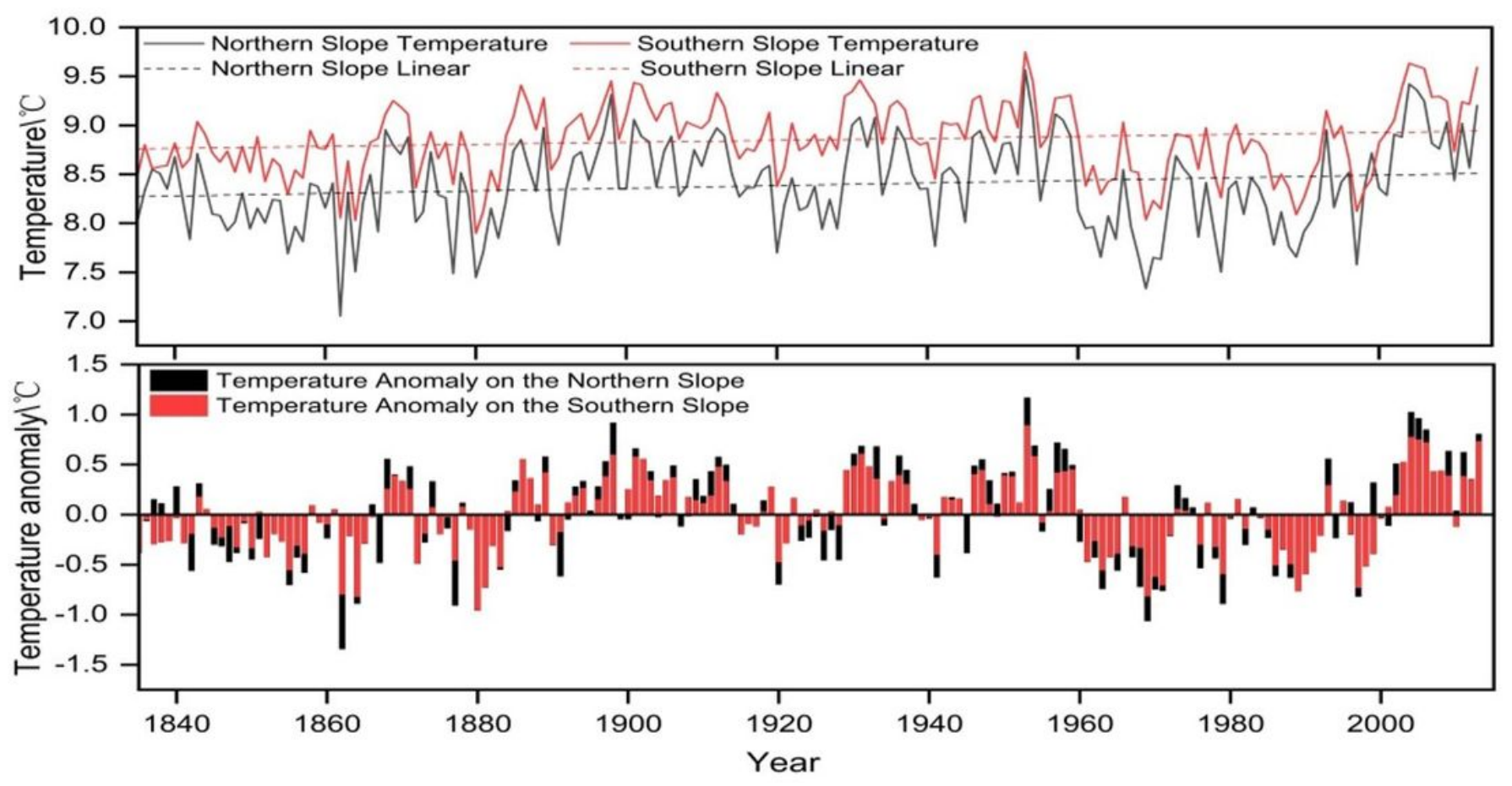

Figure 2

Temperature anomaly values from February to April on the northern and southern slopes of the Qinling Mountains

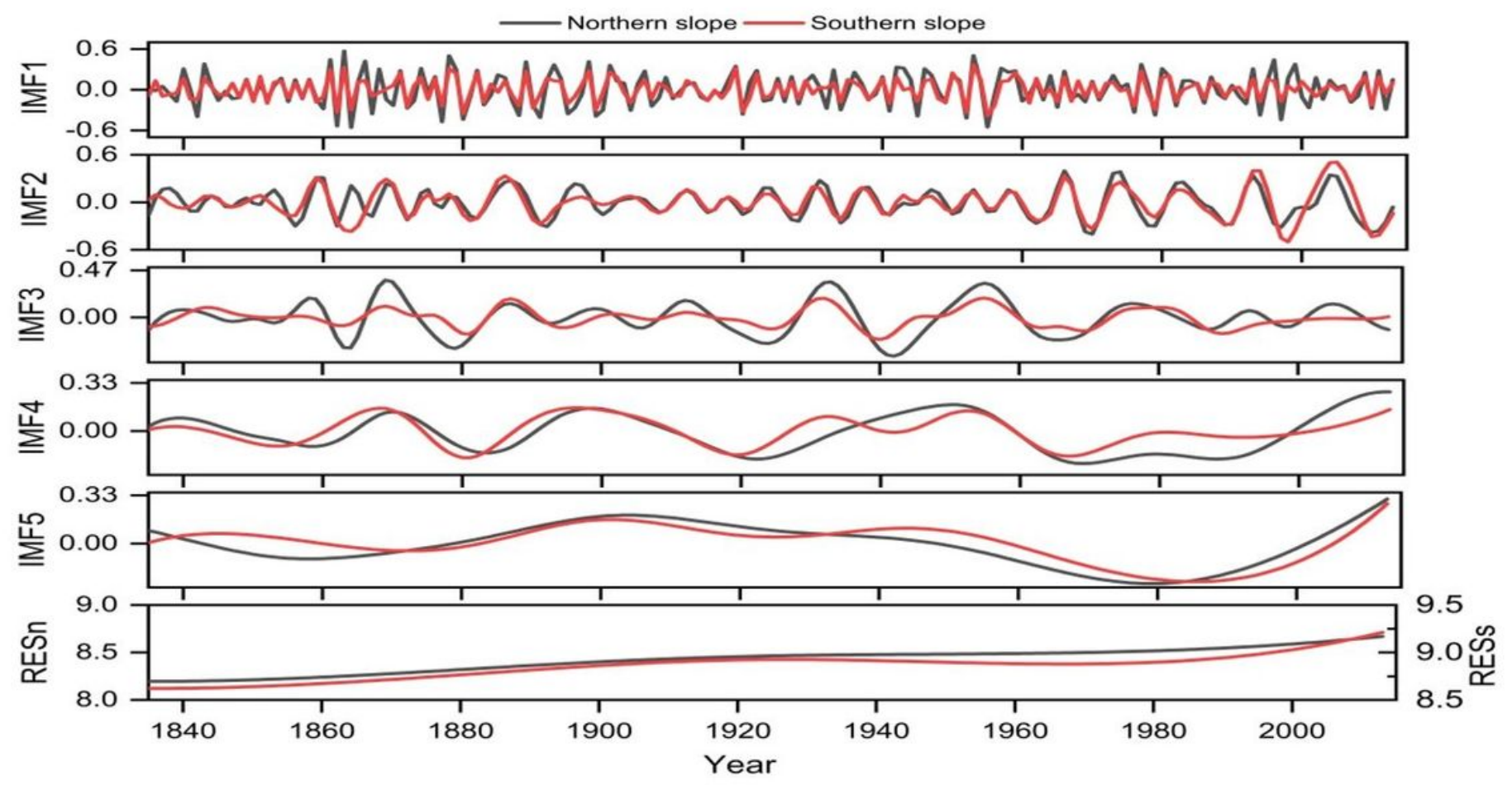

Figure 3 
Results of EEMD analysis of the northern-southern slope temperature and time series in the Qinling Mountains from February to April

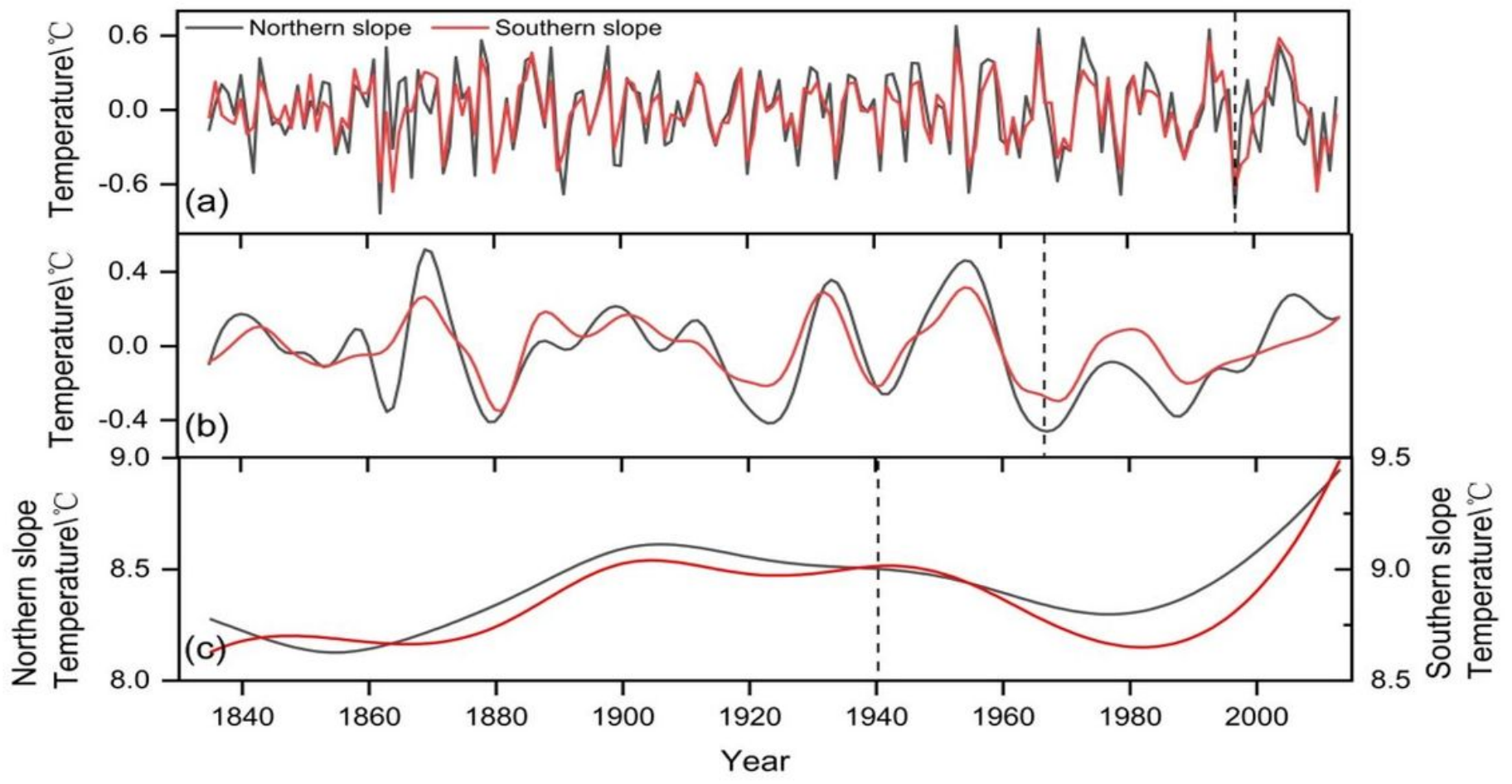

Figure 4

Multiscale reconstruction of the temperature in the Qinling area (a) Interannual scale change; (b) interdecadal scale change; (c) quasi-century scale change

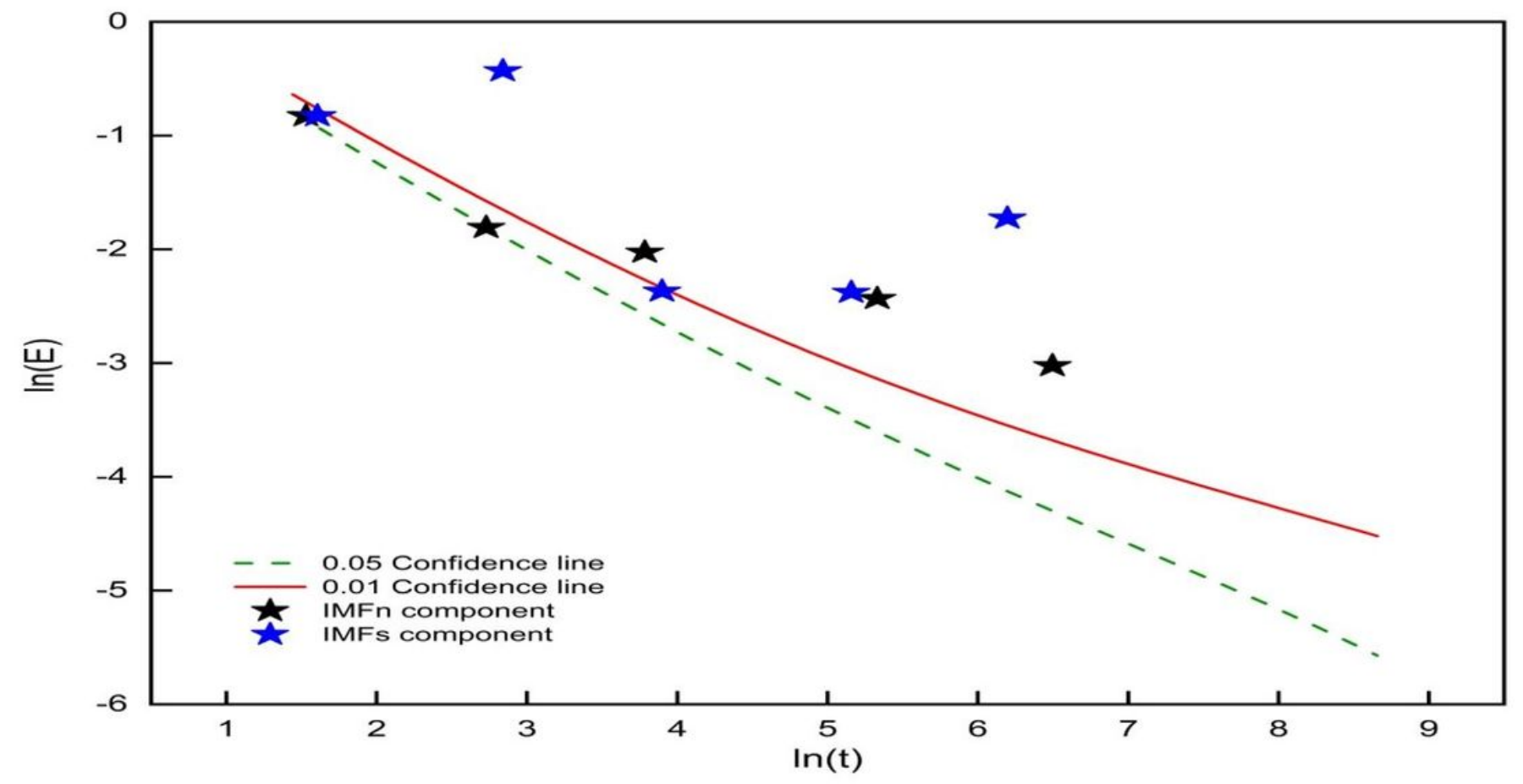

Figure 5 
Significance of the IMF component of the temperature from February-April 1835-2014 on the northern and southern slopes of the Qinling Mountains
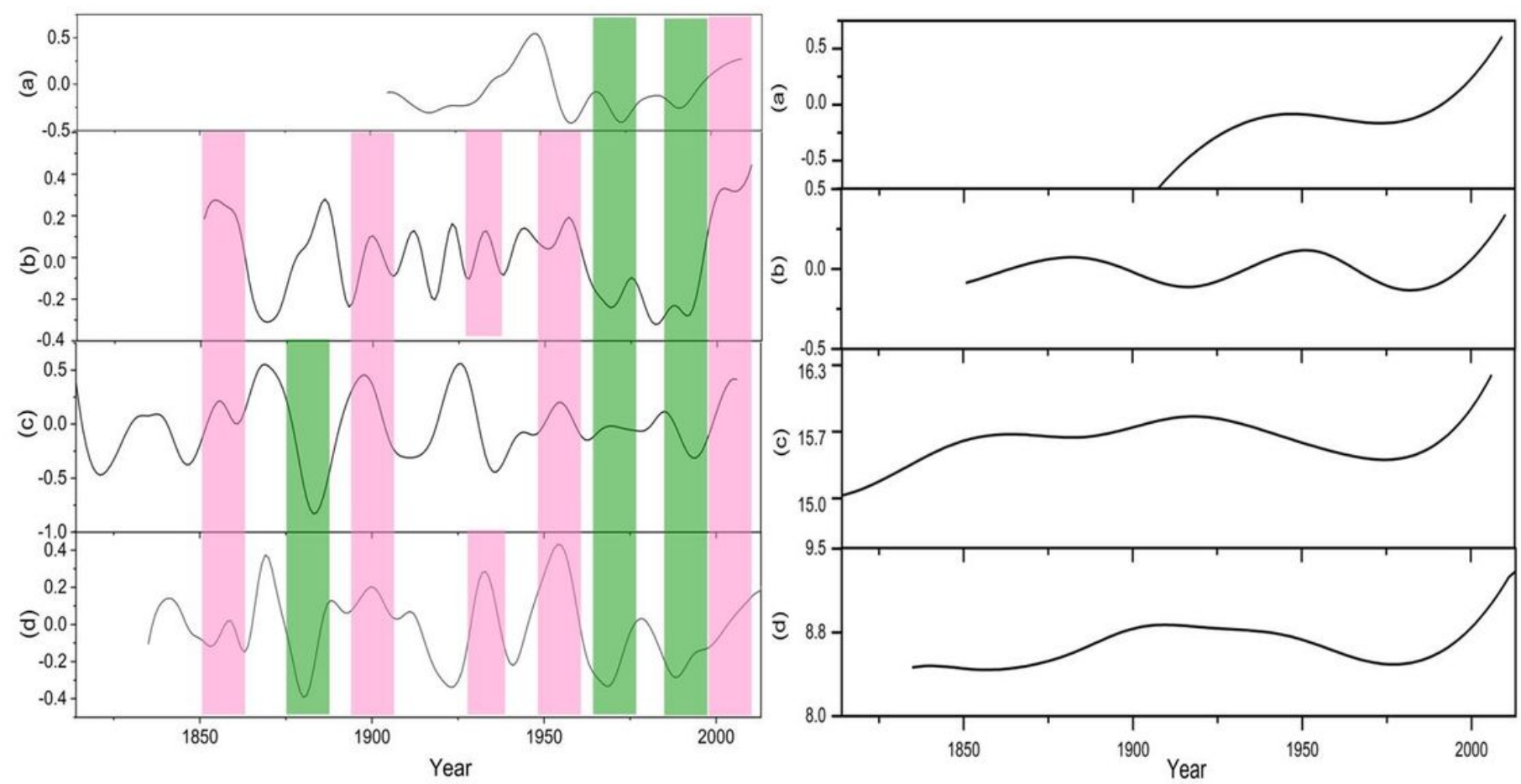

Figure 6

Comparison of the temperature in the Qinling Mountains to the rest of the time series at the interdecadal and quasi-century scales (a) China's nearly one hundred-year temperature series (Tang and Ren 2005); (b) early summer temperature sequence in the northern Sichuan Plateau (Li et al. 2015); (c) May-July temperature sequence in central Qinling (Hu et al. 2018); (d) early spring temperature in the Qinling Mountains over the past 179 years 

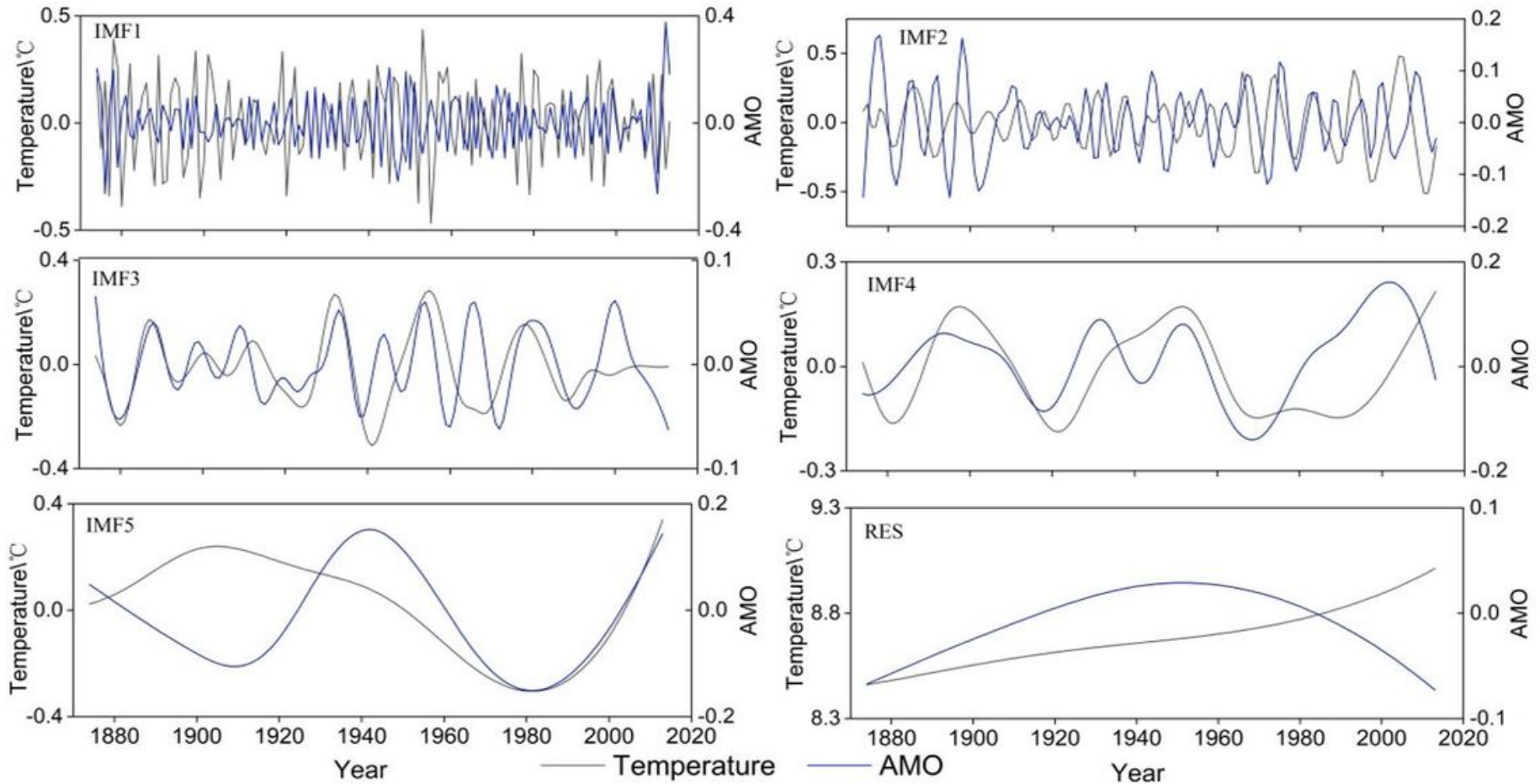

Figure 7

Comparison of the temperature and AMO index at the different time scales in the Qinling Mountains from February to April, 1874-2013
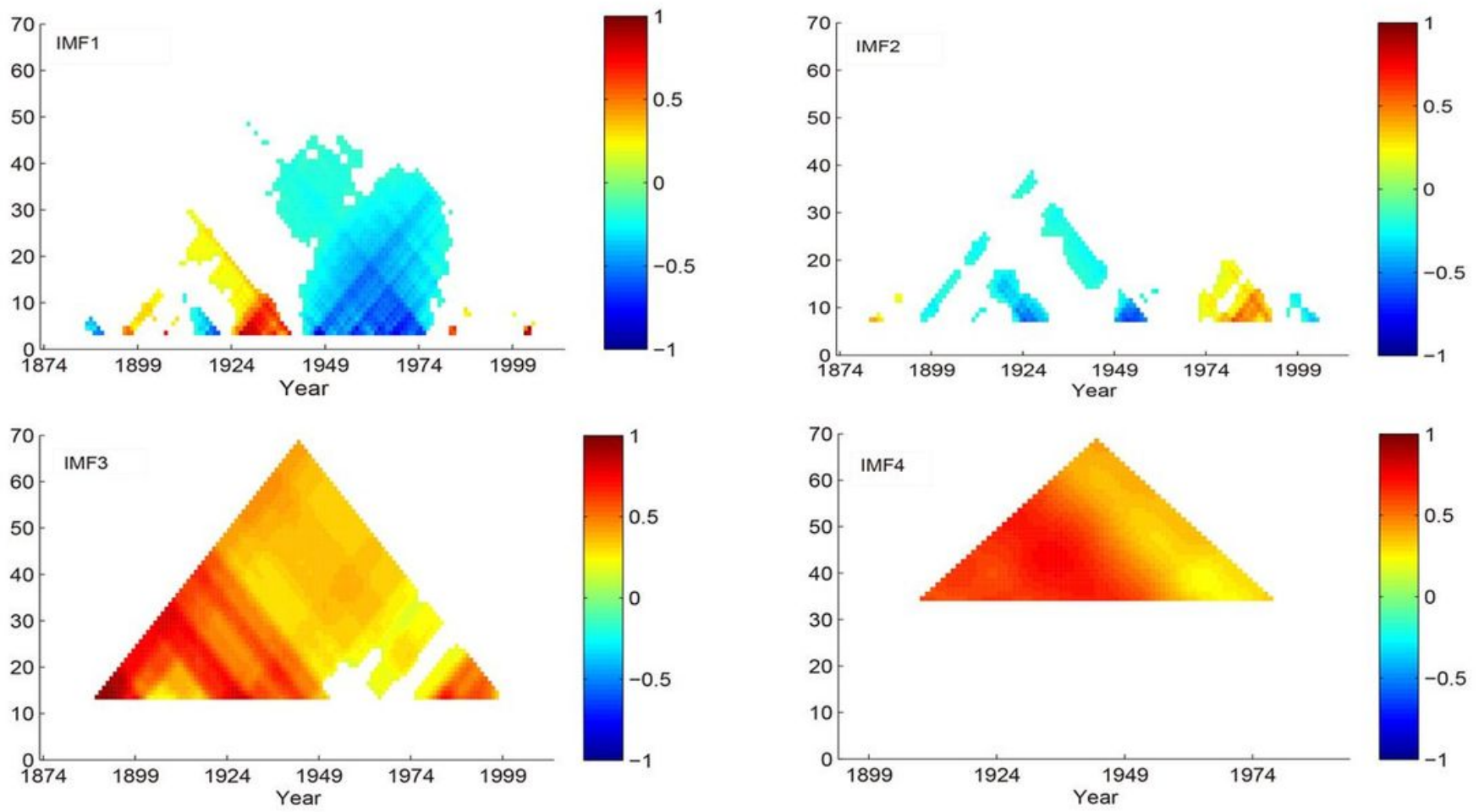

Figure 8 


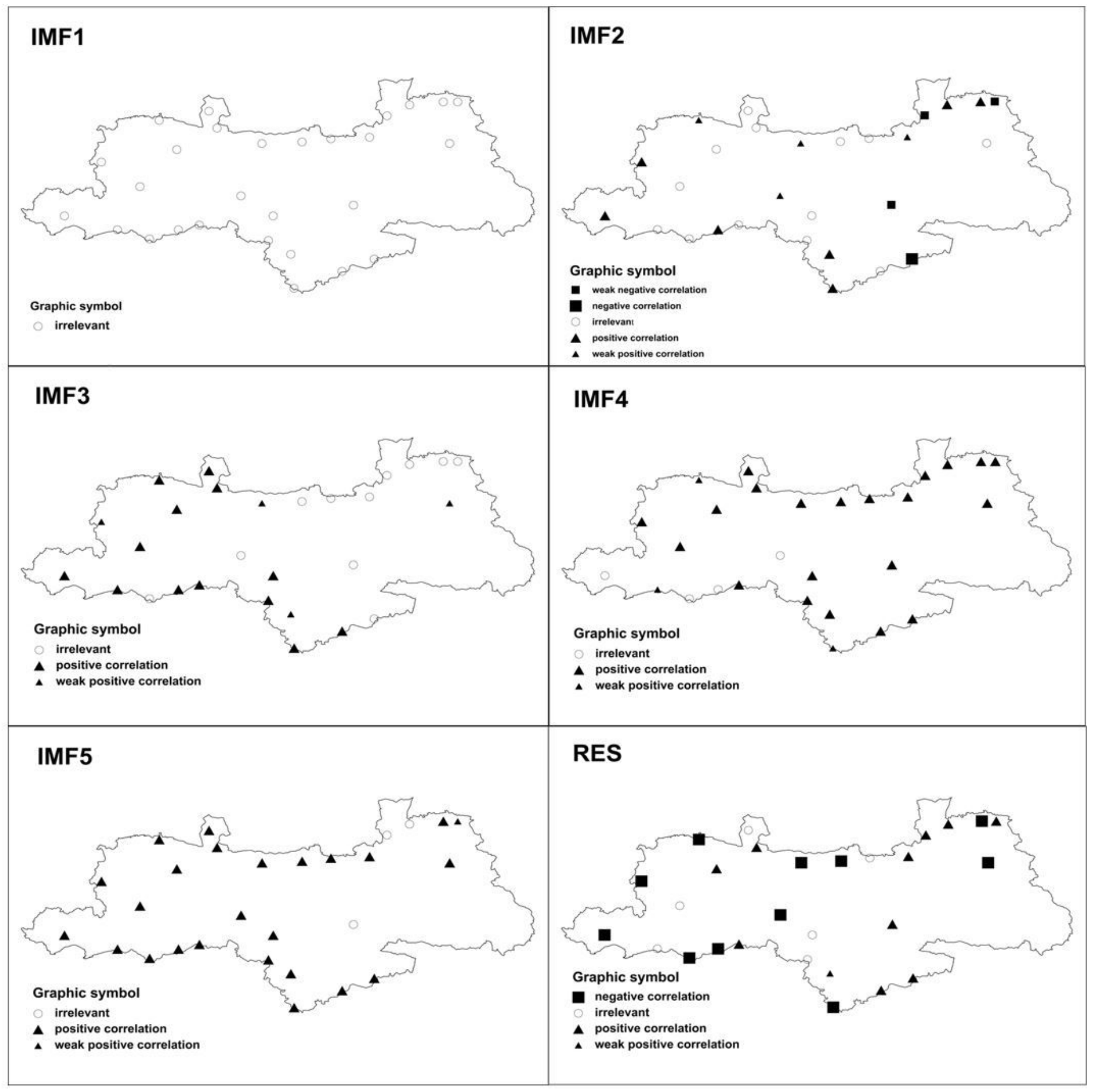

\section{Figure 9}

Spatial correlation between the temperature and AMO in February to April in the Qinling Mountains 